\title{
Мотивация «крест» в названии крестца \\ в славянских языках
}

\begin{abstract}
ЭВА КАТАЛИН ВАРГА
Semmelweis Egyetem Nyelvi Kommunikációs Igazgatóság, H-1094 Budapest, Ferenc tér 15. VARGA Éva Katalin, Directorate of Language and Communication, Semmelweis University

E-mail: vekati@gmail.com
\end{abstract}

(Received: 8 January 2018; accepted: 3 February 2018)

\begin{abstract}
In the present study, the principles of nomination of sacrum are analysed on the basis of linguistic and cultural data. The os sacrum has been considered sacred as a nidus for resurrection since antiquity. Its names are motivated by the meaning 'cross' in Slavic, Germanic, and Hungarian. In Slavic texts, this image appeared in the 16th century. This late use allows us to see it as a semantic calque of German Kreuz but the first known occurrence in German was attested in the 17th century.
\end{abstract}

Keywords: etymology, language contact, principles of nomination, historical evolution, myths and religion

Крестец - кость треугольной формы в нижней части позвоночника, образованная из пяти сросшихся позвонков. В международной анатомической номенклатуре эта кость называется os sacrum, в дословном переводе 'священная кость'. С древних времен считалось, что из этой кости возрождается тело при воскресении из мертвых. В славянских языках, а также в немецком и венгерском, название кости связывалось с образом креста. По сведению некоторых этимологических словарей (ЭСРЯ 8: 387, TESz. 2: 457-458), оно возникло в результате метафорического переноса по форме кости. Этому объяснению противоречит тот факт, что первые упоминания слова встречаются в значении части тела человека или животного, точнее 'нижняя часть позвоночника; круп лошади'. Распространение мотивации «крест» имеет явную ареальную специфику, что позволяет думать о калькировании и предположить контактное влияние немецкого как более престижного языка. Однако самое раннее упоминание соответствующего названия датируется XV веком в польском языке, двумя столетиями ранее, чем в немецком.

В данной работе нами делается попытка выяснить настоящий принцип номинации кости. После рассмотрения формирования анатомического термина os sacrum дается краткий обзор представлений о святости, приписываемой кости. Мы проведем подробный анализ названий с семантикой «крест» в немецком, польском, венгерском и русском языках, опираясь не только на данные словарей, но и цитируя и интерпретируя оригинальные тексты. В анализ включается и влияние внеязыковых факторов, таких как развитие медицины и анатомии, языческие и христианские мифы и верования. Учитывается 
и мнение о номинации анатомических структур врачей, зачастую проявляющих больший интерес к изучению возникновения анатомической терминологии, чем лингвисты.

Анатомические термины костной системы возникли или путем метафоризации по внешней форме, как scapula 'лопатка' и pelvis 'таз', или указывают на расположение анатомической структуры, как humerus 'плечевая кость' и os frontale 'лобная кость'. Номинация крестца не соответствует ни одной из двух распространенных моделей. Латинское номенклатурное название кости os sacrum в дословном переводе 'священная кость'. Это назва-

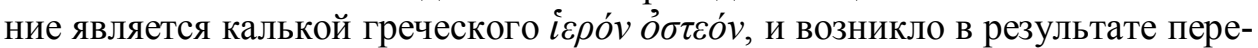

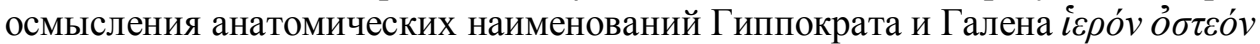

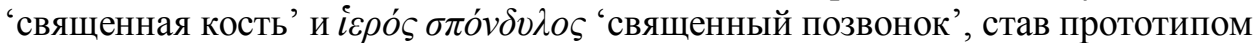
латинского sacra spina. Существительное spina в результате метафорического и метонимического переноса подверглось семантическому развитию еще в античности: 'шип, терние' > 'остистый отросток позвонка' > 'позвонок' > 'позвоночник, позвоночный столб' (OLD 1968: 1805). В греческих названиях

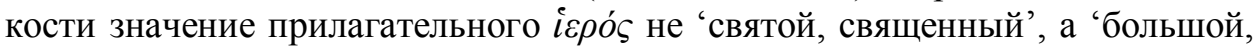
крупный'. Доказательством этой интерпретации служат и данное Гиппократом наименование $\mu \varepsilon ́ \gamma \alpha \varsigma \sigma \pi \delta ́ v \delta v \lambda o \varsigma$ 'большой позвонок', и латинские кальки других названий древних греков, возникшие под влиянием употребляемых арабскими врачами наименований, как os magnum ( $\mu \dot{\gamma} \gamma \alpha \varsigma \sigma \pi o ́ v \delta v \lambda o \varsigma)$ 'крупная кость' или os latum ( $\pi \lambda \alpha \tau \dot{~ o ́ \sigma \tau \varepsilon o ́ v) ~ ' ш и р о к а я ~ к о с т ь ' ~(H Y R T L ~ 1879: ~ 30, ~ H y R T L ~}$ 1880: 457), ставшие синонимичными до создания первой анатомической номенклатуры в конце XIX века. При калькировании когнитивная функция называния уходит на задний план или полностью исчезает. Таким образом, os

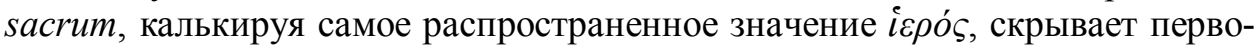
начальную мотивацию номинации кости, указание на ее размер. Однако можно предположить, что необходимость включения рассматриваемого названия в лексическую систему способствовала поискам новой вторичной мотивации к наименованию, поэтому название 'священная кость' породило целый ряд различных ассоциативных представлений.

Крестцу приписывалась священность с древних времен. Этому давали несколько объяснений: он поддерживает и защищает внутренние органы, вблизи крестца расположены гениталии. По древнему представлению мужской половой член непосредственно связан с позвоночником, и дух человеческий, возникающий в мозге, проходит в пенис через позвоночный канал. У древних майя крестец - это нижний череп, орган оплодотворения (STRoss 2007: 4). В фольклоре разных народов позвоночник человека ассоциируется с мировым столпом, соединяющим верхний и нижний мир (АндРейко 2011: 168, ПАВловА 2014: 47). В мифах Осириса, убитого и воскресшего бога древних египтян, колонна Джед представляет собой сноп пшеницы как символ нового урожая и начало новой жизни, и одновременно олицетворяет позвоночник Осириса как символ воскресения (Р РNCH 2002: 127-128). По версии Плутарха, бог был воскрешен Исидой из останков, найденных ею в стволе 
дерева тамариск (PlutaRchus: V. 26). C мифом попали на Ближний Восток представления о неразрушимой кости воскресения, из которой человек возрождается после смерти. По преданию иудеев, это кость луз, в форме миндаля, расположенная на нижнем конце позвоночника (GUÉNON 1958: 57-59). По сведению Иеронима, в комментариях к Еккл. 12.5: «florem autem amygdali [...] quidam sacram spinam interpretantur» (HiERonYMUS: 1166), то есть 'цветок миндаля [...] некоторые интерпретируют как крестец'. Расцветающее ранней весной дерево миндаля, согласно Ветхому Завету, возвещает не только конец зимы и возрождение новой жизни, но и в виде Ааронова жезла пророчит материнство Марии и пришествие Христа. Крест как распятие, превращаясь из орудия смерти и казни в символ воскресшего и торжествующего над смертью Спасителя, в ранней христианской иконографии до XII века изображался в виде живого дерева с листвой. Этот образ слился с образом мирового дерева как axis mundi и древа жизни в Раю. Славянское *krbstъ, являющееся заимствованной из древневерхненемецкого формой имени Христа, приобретшее значение 'распятие', позже и 'крест', совмещает символику христианской религии и ее центрального персонажа (ФАСМЕР 2: 374, ХЕлимский 2000: 444).

В славянских языках название крестца связывалось с образом креста. Номинация немецкого Kreuzbein и венгерского keresztcsont также основывается на семантике «крест». Ею же мотивированы литовское kryžkaulis, латышское krustu kauls, финское ristiluu, эстонское ristluи (заимствования из русского ФАСмеР 2: 374), шведское korsben, норвежское korsbein, датское kryds и термин crossbone в английской терминологии повивальных бабок XVIII-XIX веков. Однако в романских языках - кроме румынского народного названия кости osul crusii - оно не засвидетельствовано. Ареальная специфика распространения мотивации «крест» позволяет предположить калькирование. Поскольку среди упомянутых языков немецкий считается наиболее престижным, можно было бы допустить возможность контактного влияния немецкого Kreuz и Kreuzbein.

В словаре немецкого языка Аделунга фигурирует две словарные статьи Kreuz: Kreuz 1 со значением 'возвышение, круп животного, преимущественно лошади, нижняя часть спины' не имеет никакой связи с Kreuz $_{2}$ со значением 'крест'. Аделунг связывает Kreuz 1 с латинским прилагательным crassus 'сильный, крепкий, плотный' (ADELUNG 1811). Таким образом, мотивация немец-

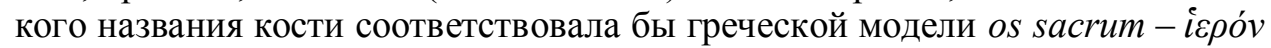

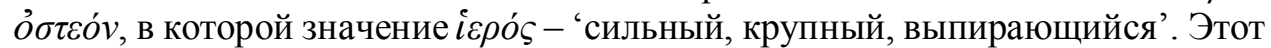
образ отражается и в другом данном греческими врачами названии $\mu \dot{\varepsilon} \gamma \alpha \varsigma$ $\sigma \pi \delta ́ v \delta v \lambda o \varsigma$ 'большой позвонок', а также в латинском названии os latum 'широкая кость'. Мнение Аделунга разделяет и анатом Гиртль: значение $\operatorname{Kreu}(t) z$ 'возвышение, круп животного', которое бросается в глаза особенно у лошади, не имеет никакой связи с христианским символом (HYRTL 1880: 458). Ссылаясь на древневерхненемецкий перевод VIII века Исидора Севильского, он относит возникновение $\mathrm{Kreuz}_{1}$ к древнейшим временам (HyRTL 1884: 32). 
Этой гипотезе противоречит то, что Kreuz и Kreuzbein в значении 'крестец' в немецком языке засвидетельствованы только в XVII веке (PFEIFER 2003: 733, DWDS). В анатомических описаниях до XVIII века употреблялось heilige Bein, дословно означающее 'священная кость', калька с os sacrum. Кроме того, в словарях немецкого языка не упоминается о возможном различном происхождении двух $\mathrm{Kreuz}$, в словаре братьев Гримм находим только один Kreuz, под значением 8 которого - 'нечто крестообразное' - указывается и значение 'нижняя часть позвоночника' (GRIMM).

В большинстве словарей не дается никаких объяснений семантического развития анатомического значения (например, МАснек 1968). Вероятно, что название крестца считается метафорой, указывающей на крестообразную форму кости и возникшей в данном языке (ЭСРЯ 8: 387, TESz. 2: 457-458). Хотя форма крестца лошади в самом деле напоминает распятие, мы склонны отвергать теорию переноса по форме по нескольким причинам. Метафору объясняют и тем, что тазобедренная кость, пересекая позвоночник, образует крест (BAŃKOWSKI 2000: 838). В связи с этим, слово с семантикой «крест» относится не к кости, а к нижней части позвоночника или к крупу животного. Далее, оно может иметь значение ‘позвоночник' и ‘позвонок’ также.

Анатомическое значение с семантикой «крест» впервые засвидетельствовано в польском языке. Самое раннее упоминание датируется концом XV века в переводе латинского контекста dum configitur spina в псалме 31.4, где слову spina в польском соответствует словосочетание chrzyptowa zyla, имеющее значение или 'позвоночник' (WoźNIAK 2002: 73), или 'позвоночный мозг' (StStp 2: 508). Однако вероятно, что прилагательное chrzyptowy принадлежит не к слову $k r z y \dot{z}$ 'крест’, а представляет собой контаминированный вариант grzbietowy/chrzebtowy/chrzybtowy от существительного grzbiet 'позвоночник' (SłStp 2: 508). Существительное $k r z y z \dot{~ в ~ з н а ч е н и и ~ ' н и ж н я я ~ ч а с т ь ~}$ позвоночника' зафиксировано с XVI века. В травниках Фалимиржа (1534) и Сенника (1568) оно употребляется обычно в форме множественного числа krzyże и в словосочетании bolenie krzyżov (SP XVI 11: 358), как и в наши дни.

Русское слово крестеи, являющееся производным от слова крест с суффиксом -bць , впервые зафиксировано позже, в 1626 году в значении 'задняя часть туловища животного', в форме множественного числа: «Мерин сър... на крестцах сьчено» (СРЯ XI-XVII 8: 41). В значении 'поясница, талия, пах' оно датируется 1676 годом, то есть на 50 лет позже: «раниль стрђлою въ крестецъ». Крестеи в форме множественного числа крессы (СРЯ XI-XVII 8: 39), кресць /кресты в значении 'позвонок’ встречается в текстах XVIII века «кресцы в теле человеку» (Романов 1997: 169); «кресты в теле человеческом» (Романов 1997: 170). Отметим, что венгерское название позвоночника gerinc в анатомических описаниях XVIII-XIX веков в форме множественного числа также означает 'позвонок': «Az hátnak gerintzeiröl (De vertebris dorfi)» (RÁcZ 1782: 18). Употребление формы множественного числа может указывать на влияние польского языка, как и в случае укр. крижі (Plur.) 'крестец', восходящее к польск. krzyże (Plur.) 'нижняя часть позвоночника' (BAŃкOWSKI 
2000: 838), но оно может объясняться и воздействием древнерусского/старославянского чересла/чресла (Plur.), вытесненного словом крестец. С точки зрения анатомии, крестец и копчик раннее считались одним целым, что отражается и в ранних синонимичных названиях крестца (os sacrum) верхняя / большая крестиовая кость, крестеи собственно называемый и копчика (оs coccygis) нижняя/малая крестиовая кость (Романов 1997: 187, 194), но маловероятно, что это может объяснить употребление множественного числа. Термин крестеи в качестве наименования крестцовой кости впервые использовал Протасов в 1749 г. как эквивалент немецкого das heilige Bein (РомАнов 1997: 187). Варианты терминов XVIII века отсылают или к месторасположению кости (например, кость крестцовая и кость репичная у лошади), или же являются калькой с латинского os sacrum (например, священная кость).

Венгерское keresztcsont 'крестцовая кость' упоминается впервые в 1578 году, в первом травнике на венгерском языке: «az farfabafoknac kiknec az kereß̧t czont fay igen iò, czepegò vizeletet meg állat» (Mel. Herb., folio 11), то есть '[кора белого тополя] ишиатикам, у которых крестец болит, очень помогает, подтекание мочи останавливает’. Автор травника епископ-кальвинист Петер Мелиус Юхас учился в Виттенберге. Кроме «трех святых языков» он владел и немецким. Главным источником его труда служила работа франкфуртского врача и ботаника Лоницера под названием Naturalis historiae opus novum (1551) в латинском издании, и Kreuterbuch - в немецком. Мелиус пополнял травник материалами не только из работ своих современников Фукса и Маттиолуса, но и древних авторов, в том числе Галена, Плиния и Диоскорида (FAZEKAS 1982: 52, 59). К сожалению, в источниках Мелиуса не фигурирует соответствующее название с семантикой «крест».

Суммируя результаты исследования, можем прийти к выводу, что первоначальное значение названий с семантикой «крест» относилось к части тела, к нижней части позвоночника человека и задней части корпуса животного, особенно лошади, и только позже стало обозначать кость, находящуюся там. Метафорический перенос по форме позвоночника возможен в том случае, если под крестом понимается только вертикальная часть обозначаемого предмета, как это отражается в первоначальном значении 'столб, шест, кол' гре-

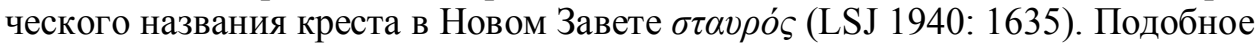
семантическое развитие наблюдается в германских родственных словах латинского crux (VAAN 2008: 147-148). Вместо представления о метафорическом переносе по форме более вероятным кажется мнение К. Мелладо Бланко, согласно которому немецкое Kreuzbein является свободным переводом (Lehnübertragung), особым типом кальки с латинского os sacrum (MELLADO Blanco 1999: 256). В случае венгерского keresztcsont тоже возникает предположение о возможности влияния латинского os sacrum (EWUng. 2: 736). Возникновению данного типа кальки помимо неточных знаний того времени об анатомии и функционировании человеческого тела содействовали и представления о кости воскресения и тот факт, что название креста неразрывно связывалось с именем Христа. 
Отсутствие ссылок в этимологических словарях и в литературе, поддерживающих контактное влияние немецкого языка, а также хронологические трудности в связи с фиксацией слова Kreuz в значении 'крестец' не позволили нам доказать гипотезу о калькировании с немецкого названия. Если в немецком языке действительно существовали $\mathrm{Kreuz}_{1}$ и $\mathrm{Kreuz}_{2}$, переходу из омонимии в полисемию и слиянию двух слов могло способствовать латинское название кости os sacrum, которое легко могло вступить в ассоциативную связь с крестом, непосредственно примыкающим к понятию 'святой' для христианина (SugAR 1987: 2061, АГАФонов 2015: 99). Дальнейший анализ семантического развития соответствующих слов в отдельных языках, выделение специальной лексики из текста травников и лечебников может подтвердить опосредованное взаимовлияние языковых и культурных отношений.

\section{Литература}

АГАФонов 2015 = АГАФонов А. Н. Этимология и семантика некоторых медицинских терминов. Вестник Смоленской государственной медичинской академии 2015/3: $97-102$.

АндРейко 2011 = АндРейко Ю. С. Композиционные особенности традиционного бурятского костюма. Terra Humana 2011/1: 168-172.

ПАВЛОВА $2014=$ ПАВЛОВА А. Н. Трансформация космологической символики марийского головного убора. Вестник Казанского государственного университета культуры и искусств 2014/4-2: 46-50.

Романов 1997 = Романов Н. А. Русская анатомическая терминология ХVIII века. Кн. 1. Остеология. Смоленск, 1997.

СРЯ XI-XVII = Словарь русского языка XI-XVII вв. Т. 1-30. Москва, 1975-2015.

ФАСМЕР = ФАСМЕР Макс: Этимологический словарь русского языка. Т. 1-4. Москва, $1986-1987$.

Хелимский 2000 = ХЕлимский Е. А. Компаративистика, уралистика. Лекиии и статьи. Москва, 2000.

ЭСРЯ = Этимологический словарь русского языка. Т. 1-11. Москва, 1963-2014.

ADELUNG 1811 = AdeLung J. Ch. Grammatisch-kritisches Wörterbuch der hochdeutschen Mundart (1811). http://lexika.digitale-sammlungen.de/adelung/band/bsb00009132.

BAŃKOWSKI 2000 = BAŃKOwSKI A. Etymologiczny stownikjęzyka polskiego. Warszawa, 2000.

DWDS = Das Digitale Wörterbuch der deutschen Sprache. http://www.dwds.de.

EWUng. = BENKÖ Loránd (szerk.): Etymologisches Wörterbuch des Ungarischen 1-3. Budapest, 1993-1997.

FAZEKAS 1982 = FAZEKAS Árpád: A magyar nyelvű herbárium-irodalomról. Orvostörténeti Közlemények 97-99 (1982): 43-64.

GRIMM = Deutsches Wörterbuch von Jacob Grimm und Wilhelm Grimm. http://woerter buchnetz.de/cgi-bin/WBNetz/wbgui_py?sigle=DWB.

GuÉNON 1958 = GuÉNON R. Le Roi du Monde. Paris, 1958. http://classiques.uqac.ca/clas siques/guenon_rene/roi_du_monde/roi_du_monde.pdf.

HIERONYMUS $=$ S. Eusebii Hieronymi Stridonensis presbyteri Commentarius in Ecclesiasten. Documenta catholica omnia. http://www.documentacatholicaomnia.eu/02m/03470420,_Hieronymus,_Commentarius_In_Ecclesiasten,_MLT.pdf. 
Hyrtl $1879=$ Hyrtl J. Das Arabische und Hebräische in der Anatomie. Wien, 1879.

Hyrtl $1880=$ Hyrtl J. Onomatologia anatomica. Geschichte und Kritik der anatomischen Sprache der Gegenwart. Wien, 1880.

Hyrtl 1884 = Hyrtl J. Die alten deutschen Kunstworte der Anatomie. Wien, 1884.

LSJ 1940 = LidDELl H. G., SCOTt R. A Greek-English Lexicon. Revised and augmented throughout by Sir Henry Stuart Jones with the assistence of Roderick McKenzie. Oxford, 1940.

MACHEK 1968 = MACHEK V. Etymologický slovnik jazyka českého. Praha, 1968.

Mel. Herb. = HoRHi Melius P. Herbarivm. Az faknac fvveknec nevekrôl, terméb́etekröl, és haß̧nairól. Magyar nyelwre, és ez rendre hoszta az Doctoroc Könyueibŏl az Horhi Melius Peter. Colofuár, 1578.

Mellado Blanco 1999 = Mellado Blanco C. Das bildliche Potential der deutschen Körperteilbezeichnungen. Muttersprache 109 (1999): 246-260.

OLD 1968 = Glare P. G. W. (ed.) Oxford Latin Dictionary. Oxford, 1968.

PfEIFER 2003 = PFEIFER W. (Hrsg.) Etymologisches Wörterbuch des Deutschen. München, 2003.

PINCH 2002 = Pinch G. Handbook of Egyptian Mythology. Santa Barbara, Ca. etc., 2002.

PlutARCHUS $=$ PlutARCHUS: Moralia . (Bibliotheca scriptorum Graecorum et Romanorum Teubneriana.) Leipzig, 1978.

RÁCz 1782 = RÁCz Sámuel: A borbélyságnak eleji, mellyeket németül, 's deákul ki-adott Plenck Jósef. Pest és Buda, 1782.

SłStp = URBAŃCZYK S. (red.) Słownik staropolski. T. 1-11. Wrocław-Warszawa-KrakówGdańsk-Łódź, 1953-2002.

SP XVI = Słownik polszczyzny XVI wieku . T. 1-36. Wrocław-Warszawa-Kraków-Gdańsk, 1966-2012.

Stross 2007 = Stross B. The Mesoamerican Sacrum Bone. Doorway to the Otherworld. FAMSI Journal of the Ancient Americas 2007. 1-54. http://research.famsi.org/aztlan/ uploads/papers/stross-sacrum.pdf.

Sugar 1987 = Sugar O. How the Sacrum Got Its Name. The Journal of the American Medical Association 257 (1987): 2061-2063.

TESz. = BENKŐ Loránd (szerk.): A magyar nyelv történeti-etimológiai szótára 1-4. Budapest, 1967-1984.

VAAN $2008=$ VAAN M. Etymological Dictionary of Latin and the other Italic Languages. Leiden-Boston, 2008.

WoźNIAK 2002 = WoźNIAK E. Stownictwo i frazeologia Psałterza Krakowskiego (1532) na tle ówczesznych przekładów biblijnych. Lódź, 2002. 